\title{
29\% $\mathrm{P}_{2} \mathrm{O}_{5}$ Phosphoric Acid Desulphation: Improving the Performance of the Unit of Concentration
}

\author{
Abderrahmane Aboulhassane, Abderrahim Najah El Idrissi, Yassine Bounou, Driss Zakaria* \\ Laboratory of Physical Chemistry of Materials (LPCM), Department of Chemistry, Faculty of Science, Chouaïb Doukkali \\ University, El Jadida, Morocco \\ Email: *zakaria.d@ucd.ac.ma
}

How to cite this paper: Aboulhassane, A., El Idrissi, A.N., Bounou, Y. and Zakaria, D. (2019) 29\% $\mathrm{P}_{2} \mathrm{O}_{5}$ Phosphoric Acid Desulphation: Improving the Performance of the Unit of Concentration. American Journal of Analytical Chemistry, 10, 65-75. https://doi.org/10.4236/ajac.2019.103006

Received: January 5, 2019

Accepted: March 5, 2019

Published: March 8, 2019

Copyright $\odot 2019$ by author(s) and Scientific Research Publishing Inc. This work is licensed under the Creative Commons Attribution International License (CC BY 4.0).

http://creativecommons.org/licenses/by/4.0/

\begin{abstract}
Clogging in the heat exchangers of the phosphoric acid concentration unit is a phenomenon which hinders the proper functioning of the installation. It results in the accumulation of undesirable solid deposits on the pipes and consequently a decrease of its performance. This deposit is mainly anhydrous or hemihydrate gypsum in addition to $\mathrm{Na}_{2} \mathrm{SiF}_{6}$. Phosphoric acid desulphation before its concentration step allows reducing this undesirable effect. Barium carbonate is used for the retention of sulphate ions using a simple experimental protocol which can easily be inserted into the phosphoric acid manufacturing. Four factors: quality of the phosphoric acid to be concentrated, amount of barium carbonate, temperature and time, were studied using design of experiment (DOE) methodology with two-level full factorial design strategy in order to assess their effects on desulphation. Only the first two factors have significant effects. Therefore, for effective sulphate removal, the validated statistical model $\left(R^{2}=99.96 \%\right)$ allows to predict the amount of barium carbonate to be used, depending on quality of the phosphoric acid to be concentrated and using the available temperature and time in the industrial process.
\end{abstract}

\section{Keywords}

Phosphoric Acid, Barium Carbonate, Desulphation, Protocol Modeling, Full Factorial Design

\section{Introduction}

Manufacturing of phosphoric acid from natural phosphate by sulfuric acid attack inevitably produces impurities such as sulphates, fluorine, organic matter 
and heavy metals. Sulphate ions, in particular, have about $2 \%$ weight, and affect undoubtedly the efficiency of $29 \% \mathrm{P}_{2} \mathrm{O}_{5}$ phosphoric acid concentration unit, due to the solid formation which causes premature clogging of the phosphoric acid concentration unit. Consequently, there is a $20 \%$ or even $30 \%$ if one takes into account the washing downtime and the degradation of the heat exchangers, thus increasing the operating cost. The physical-chemical characterizations allowed its identification. In order to minimize the formation of the solid during the phosphoric acid concentration step, we propose to desulphate $29 \% \mathrm{P}_{2} \mathrm{O}_{5}$ phosphoric acid by barium carbonate using a simple experimental protocol that can be inserted into the industrial process. Design of experiments methodology is used for modeling the process and to determine the optimum conditions depending on the quality of the acid to be pretreated.

\section{Instrumentation}

Characterization of sediment were carried out by X-ray diffraction (XRD) on the powder (Bruker advance D8 eco diffractometer with CuK $\alpha$ radiation $\lambda=1.5418 \AA$ ). Sulphate was determined by titration with barium chloride and sulfonazo-3 $\left(\mathrm{C}_{22} \mathrm{H}_{12} \mathrm{~N}_{4} \mathrm{Na}_{4} \mathrm{O}_{14} \mathrm{~S}_{4}\right)$ as an indicator. The determination of phosphoric acid impurities was carried out by inductively coupled plasma-emission spectroscopy ICP-OES (Jobin Yvon ULTIMA 2).

\section{Phosphoric Acid}

Phosphoric acid was produced from Moroccan fluoroapatite by wet process according to the following equation [1] [2]:

$$
\mathrm{Ca}_{10}\left(\mathrm{PO}_{4}\right)_{6} \mathrm{~F}_{2}+10 \mathrm{H}_{2} \mathrm{SO}_{4}+10 x \mathrm{H}_{2} \mathrm{O} \rightarrow 6 \mathrm{H}_{3} \mathrm{PO}_{4}+10 \mathrm{CaSO}_{4} \cdot x \mathrm{H}_{2} \mathrm{O} \downarrow+2 \mathrm{HF} \uparrow
$$

Dependent on the process conditions, such as the temperature, either calcium sulphate hemihydrates $(x=1 / 2, \mathrm{HH})$ or dehydrate $(x=2$, DH or phospho-gypsum) is formed. In the dihydrate process $(\mathrm{DH})$, the temperature of the reactor is maintained less than $80^{\circ} \mathrm{C}$. The obtained phosphoric acid contains $26 \%$ to $29 \%$ $\mathrm{P}_{2} \mathrm{O}_{5}$ with the main impurities shown in Table 1.

The profile of the concentrated acid (exiting the concentration step), obtained by water evaporation under vacuum, is shown in Table 2 .

Table 1. Chemical composition of the phosphoric acid before concentration $(\rho=1.267$ $\left.\mathrm{g} / \mathrm{cm}^{3}\right)$.

\begin{tabular}{cccccccccccc}
\hline Elements & $\mathrm{P}_{2} \mathrm{O}_{5}$ & Solid & $\mathrm{SO}_{4}^{2-}$ & $\mathrm{CaO}$ & $\mathrm{MgO}$ & $\mathrm{Fe}_{2} \mathrm{O}_{3}$ & $\mathrm{Al}_{2} \mathrm{O}_{3}$ & $\mathrm{SiO}_{2}$ & $\mathrm{~F}^{-}$ & $\mathrm{Na}_{2} \mathrm{O}$ & $\mathrm{K}_{2} \mathrm{O}$ \\
\hline \% weigh & 27.12 & 0.05 & 1.73 & 0.73 & 1.62 & 0.27 & 0.16 & 0.42 & 0.73 & 0.06 & 0.06 \\
\hline
\end{tabular}

Table 2. Chemical composition of the phosphoric acid after concentration $(\rho=1.681$ $\left.\mathrm{g} / \mathrm{cm}^{3}\right)$.

\begin{tabular}{cccccccccccc}
\hline Elements & $\mathrm{P}_{2} \mathrm{O}_{5}$ & Solid & $\mathrm{SO}_{4}^{2-}$ & $\mathrm{CaO}$ & $\mathrm{MgO}$ & $\mathrm{Fe}_{2} \mathrm{O}_{3}$ & $\mathrm{Al}_{2} \mathrm{O}_{3}$ & $\mathrm{SiO}_{2}$ & $\mathrm{~F}^{-}$ & $\mathrm{Na}_{2} \mathrm{O}$ & $\mathrm{K}_{2} \mathrm{O}$ \\
\hline \% weigh & 54.09 & 2.24 & 2.95 & 0.68 & 0.97 & 0.51 & 0.55 & 0.17 & 0.52 & 0.38 & 0.1 \\
\hline
\end{tabular}




\section{Deposit Identification}

The deposited solid during the concentration of $29 \% \mathrm{P}_{2} \mathrm{O}_{5}$ phosphoric acid is identified using ICP-OES, X-ray diffraction and by monitoring the variation of major impurity mass as a function of the $\% \mathrm{P}_{2} \mathrm{O}_{5}$ evolution during the phosphoric acid concentration. Table 3 and Figure 1 show that the solid formed is mainly gypsum [3], sodium fluosilicate [4] and other minor constituents.

Table 4 shows the variation of volume, density, $\mathrm{P}_{2} \mathrm{O}_{5}$, solid and major impurities during the concentration of phosphoric acid.

Table 3. ICP-OES analysis results for the deposited solid in the heat-exchanger.

\begin{tabular}{ccccccccccc}
\hline Elements & $\mathrm{SO}_{4}^{2-}$ & $\mathrm{CaO}$ & $\mathrm{Al}_{2} \mathrm{O}_{3}$ & $\mathrm{~F}$ & $\mathrm{MgO}$ & $\mathrm{Na}_{2} \mathrm{O}$ & $\mathrm{SiO}_{2}$ & $\mathrm{~K}_{2} \mathrm{O}$ & $\mathrm{Fe}_{2} \mathrm{O}_{3}$ & $\mathrm{P}_{2} \mathrm{O}_{5}$ \\
\hline \% weigh & 49.5 & 33.5 & 2.75 & 2.5 & 1.26 & 0.56 & 0.52 & 0.06 & 0.05 & 1.75 \\
\hline
\end{tabular}

Table 4. Profile variation of phosphoric acid during the concentration step.

\begin{tabular}{|c|c|c|c|c|c|c|c|c|c|c|}
\hline \multicolumn{2}{|c|}{ Volume of acid (litre) } & 1 & 0.851 & 0.727 & 0.651 & 0.571 & 0.514 & 0.487 & 0.414 & 0.34 \\
\hline \multicolumn{2}{|c|}{ Density (g/litre) } & 1292 & 1330 & 1377 & 1424 & 1483 & 1530 & 1557 & 1645 & 1765 \\
\hline \multirow{2}{*}{$\mathrm{P}_{2} \mathrm{O}_{5}$} & $\% \mathrm{w}$ & 27.5 & 31.3 & 35.4 & 38.3 & 41.9 & 45.1 & 46.8 & 52.1 & 59.2 \\
\hline & weigh (g) & 354.78 & 354.78 & 354.78 & 354.78 & 354.78 & 354.78 & 354.78 & 354.78 & 354.78 \\
\hline \multirow{2}{*}{ Solid (Ts) } & $\% \mathrm{w}$ & 0.08 & 0.1 & 0.12 & 0.24 & 0.66 & 1.24 & 1.83 & 1.15 & 1.04 \\
\hline & weigh (g) & 1.03 & 1.13 & 1.2 & 2.22 & 5.591 & 9.76 & 13.9 & 7.83 & 6.23 \\
\hline \multirow{2}{*}{$\mathrm{Al}_{2} \mathrm{O}_{3}$} & $\% \mathrm{w}$ & 0.21 & 0.23 & 0.28 & 0.29 & 0.34 & 0.36 & 0.38 & 0.42 & 0.45 \\
\hline & weigh (g) & 2.71 & 2.6 & 2.8 & 2.69 & 2.88 & 2.83 & 2.88 & 2.86 & 2.7 \\
\hline \multirow{2}{*}{$\mathrm{Fe}_{2} \mathrm{O}_{3}$} & $\% \mathrm{w}$ & 0.27 & 0.3 & 0.35 & 0.38 & 0.42 & 0.45 & 0.47 & 0.52 & 0.57 \\
\hline & weigh (g) & 3.49 & 3.4 & 3.5 & 3.52 & 3.558 & 3.54 & 3.56 & 3.54 & 3.42 \\
\hline \multirow{2}{*}{$\mathrm{MgO}$} & $\% \mathrm{w}$ & 0.47 & 0.53 & 0.6 & 0.65 & 0.73 & 0.74 & 0.77 & 0.91 & 1 \\
\hline & weigh (g) & 6.07 & 6 & 6.01 & 6.02 & 6.184 & 5.83 & 5.84 & 6.196 & 5.99 \\
\hline \multirow{2}{*}{$\mathrm{CaO}$} & $\% \mathrm{w}$ & 0.09 & 0.07 & 0.04 & 0.03 & 0.02 & 0.01 & 0.01 & 0.01 & 0.01 \\
\hline & weigh (g) & 1.16 & 0.79 & 0.4 & 0.28 & 0.169 & 0.08 & 0.08 & 0.068 & 0.06 \\
\hline \multirow{2}{*}{$\mathrm{SO}_{4}^{2-}$} & $\% \mathrm{w}$ & 1.46 & 1.61 & 1.72 & 1.88 & 1.97 & 2.14 & 2.19 & 2.42 & 2.73 \\
\hline & weigh (g) & 18.9 & 18.2 & 17.2 & 17.4 & 16.69 & 16.8 & 16.6 & 16.48 & 16.4 \\
\hline \multirow{2}{*}{$\mathrm{SiO}_{2}$} & $\% \mathrm{w}$ & 0.35 & 0.40 & 0.44 & 0.4 & 0.32 & 0.22 & 0.16 & 0.07 & 0.02 \\
\hline & weigh (g) & 4.52 & 4.53 & 4.41 & 3.71 & 2.711 & 1.73 & 1.21 & 0.477 & 0.12 \\
\hline \multirow{2}{*}{$\mathrm{F}^{-}$} & $\% \mathrm{w}$ & 0.09 & 0.08 & 0.08 & 0.07 & 0.06 & 0.05 & 0.04 & 0.03 & 0.03 \\
\hline & weigh (g) & 1.16 & 0.91 & 0.8 & 0.65 & 0.508 & 0.39 & 0.3 & 0.204 & 0.18 \\
\hline \multirow{2}{*}{$\mathrm{Na}_{2} \mathrm{O}$} & $\% \mathrm{w}$ & 0.05 & 0.04 & 0.03 & 0.02 & 0.01 & 0.01 & 0.01 & 0.01 & 0.09 \\
\hline & weigh (g) & 0.65 & 0.45 & 0.3 & 0.19 & 0.085 & 0.08 & 0.08 & 0.068 & 0.54 \\
\hline \multirow{2}{*}{$\mathrm{K}_{2} \mathrm{O}$} & $\% \mathrm{w}$ & 0.03 & 0.03 & 0.03 & 0.03 & 0.03 & 0.03 & 0.03 & 0.04 & 0.06 \\
\hline & weigh (g) & 0.39 & 0.34 & 0.3 & 0.28 & 0.254 & 0.24 & 0.23 & 0.272 & 0.36 \\
\hline
\end{tabular}




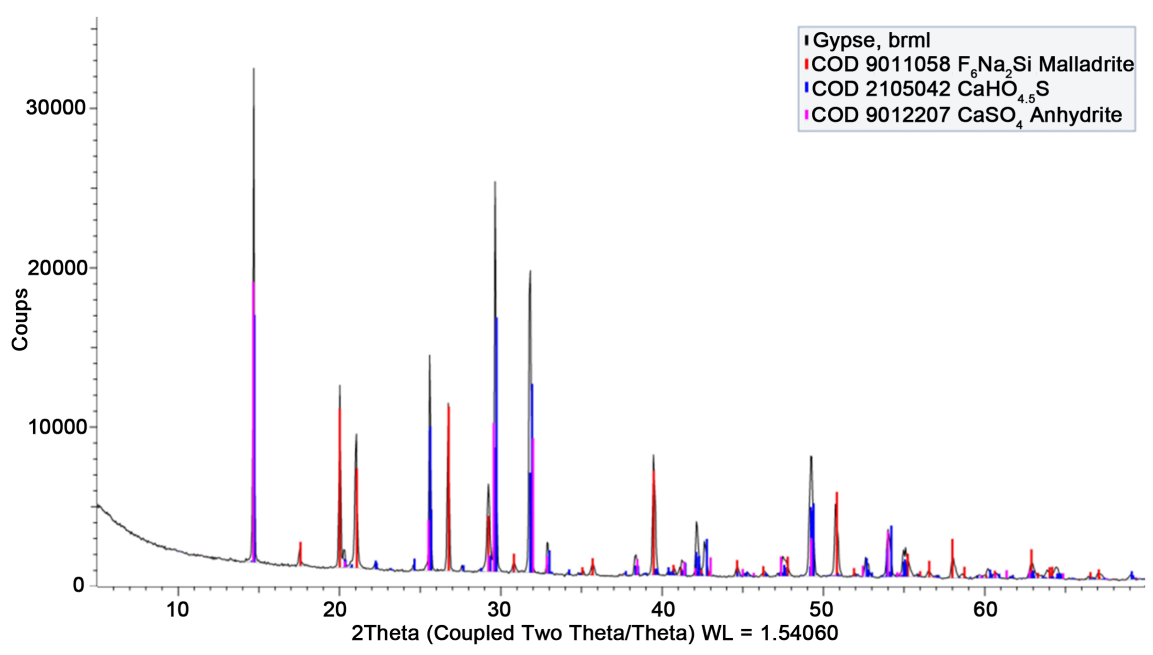

Figure 1. X-ray diffraction for the deposited solid.

Figure 2 shows the profile variation of phosphoric acid during the concentration step. The masses of $\mathrm{SO}_{4}^{2-}, \mathrm{CaO}, \mathrm{F}^{-}, \mathrm{SiO}_{2}, \mathrm{~K}_{2} \mathrm{O}$ and $\mathrm{Na}_{2} \mathrm{O}$ are decreased, while the masses of $\mathrm{MgO}, \mathrm{Al}_{2} \mathrm{O}_{3}$ and $\mathrm{Fe}_{2} \mathrm{O}_{3}$ remain virtually constant during the concentration. This explains the formation of gypsum and $\left(\mathrm{Na}, \mathrm{K}_{2} \mathrm{SiF}_{6}\right.$. From $47 \%$ of $\mathrm{P}_{2} \mathrm{O}_{5}$, dissolution of the solid and especially the sodium or potassium fluosilicate due to the evaporation of fluorine and silicon in the form of HF and $\mathrm{SiF}_{4}$ [5] is observed, which leads to an increase in the solubility of $(\mathrm{Na}, \mathrm{K})_{2} \mathrm{SiF}_{6}$ (Figure 2(a)) and consequently the decrease of its content in the formed solid.

Solid deposit accumulation in the heat exchangers reduces the phosphoric acid cross-section and causes additional thermal resistance which subsequently increases the steam specific consumption and the pressure inside the heat-exchangers (Figure 3) [6]. As a result, significant decrease in productivity can be estimated to $30 \%$ less per production cycle (7 days).

In the light of these results, it is recommended to avoid the formation of this deposit by desulphation of phosphoric acid using barium carbonate before the concentration step.

\section{Desulphation of $29 \% \mathrm{P}_{2} \mathrm{O}_{5}$ Phosphoric Acid}

The protocol of $29 \% \mathrm{P}_{2} \mathrm{O}_{5}$ phosphoric acid desulphation is judiciously chosen to be easily inserted into the phosphoric acid manufacturing process (Figure 4). Volume of phosphoric acid containing an initial quantity of $\mathrm{H}_{2} \mathrm{SO}_{4}\left(X_{1}=\right.$ quantity of initial $\mathrm{H}_{2} \mathrm{SO}_{4}$ per volume of acid) is heated to the desired temperature $\left(X_{3}\right)$ in a stirred reactor and then a quantity $\left(X_{2}\right)$ of $\mathrm{BaCO}_{3}$ is introduced. After a reaction time $\left(X_{4}\right)$, the mixture is decanted to obtain $29 \% \mathrm{P}_{2} \mathrm{O}_{5}$ acid intended to be concentrated with a low level of sulphate to prevent solid formation at the heat exchangers.

In order to determine the optimum conditions for the desulphation process, we proceed by modeling the amount of residual $\mathrm{H}_{2} \mathrm{SO}_{4}$ as a function of the inlet phosphoric acid quality and the operating conditions $(\mathrm{q}, \mathrm{T}, \mathrm{t})$. 


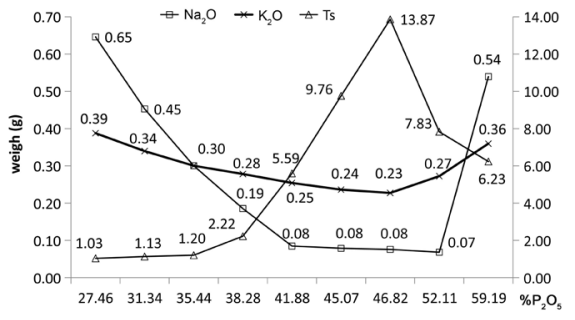

(a)

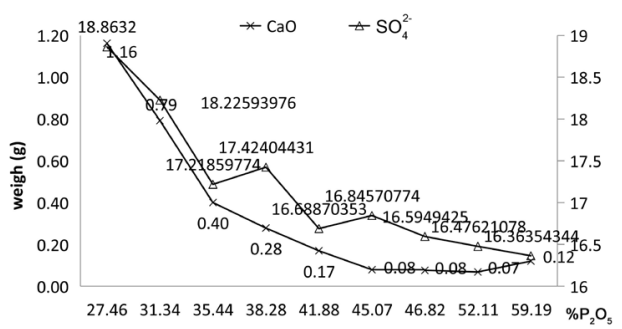

(c)

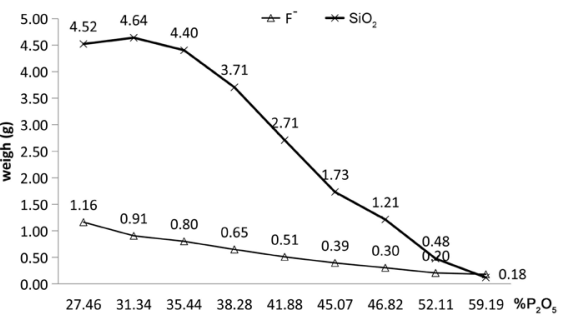

(b)

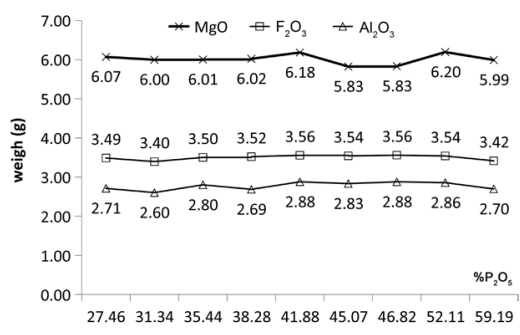

(d)

Figure 2. Profile variation of phosphoric acid during the concentration step as a function of the $\mathrm{P}_{2} \mathrm{O}_{5}$ rate.

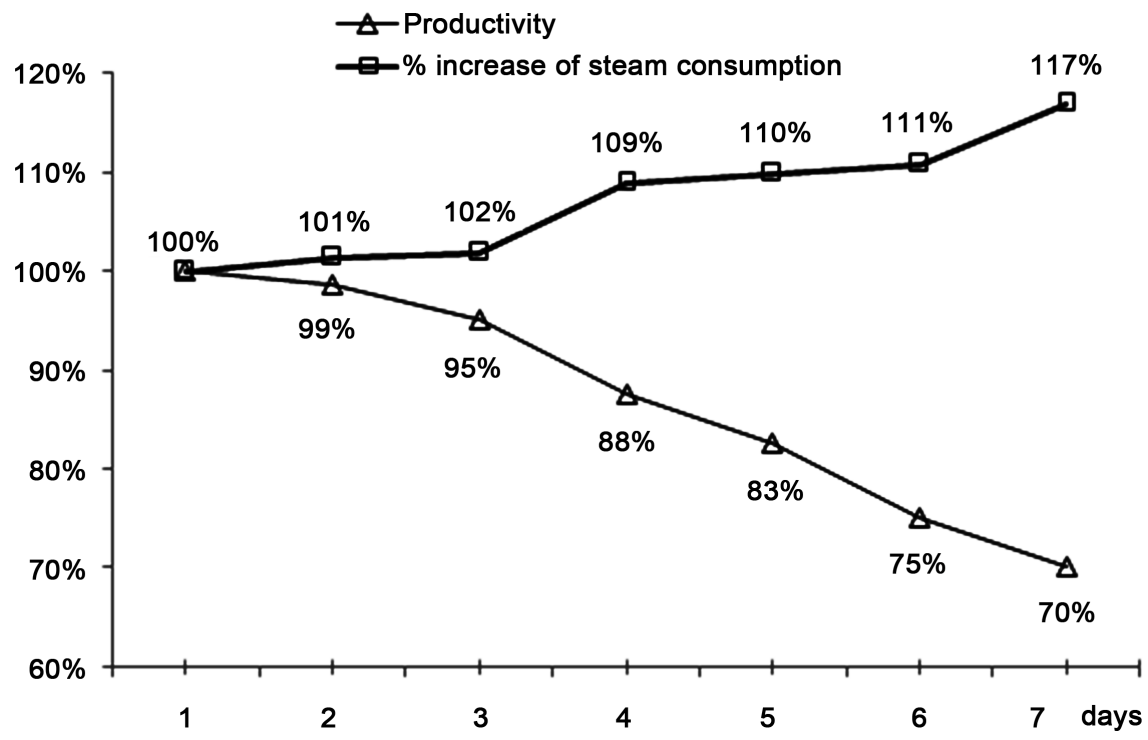

Figure 3. \% increase of steam consumption and productivity decrease during per production cycle.

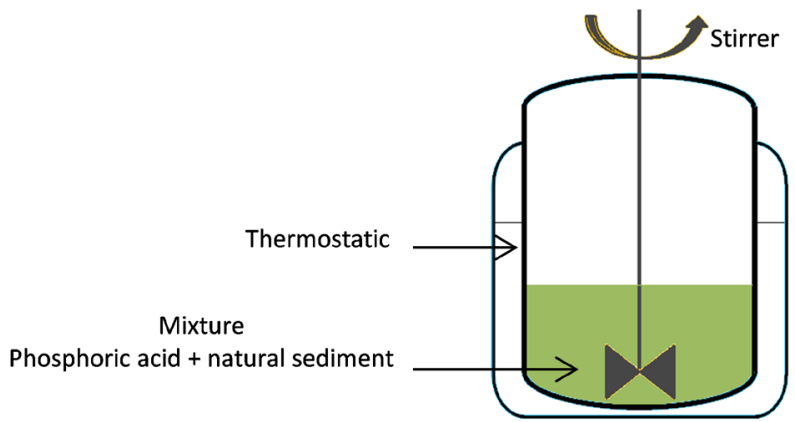

Figure 4. Experimental device for the desulphation of the $29 \% \mathrm{P}_{2} \mathrm{O}_{5}$ phosphoric acid. 


\section{Results and Discussion}

DOE methodology with two-levels full factorial design strategy, which assumes that the mean response can be adjusted correctly using a linear model, reduces the number of trials to determine with great precision the effects of the factors and their interactions on the response and avoids the alias phenomenon [7]. Four factors were studied to determine their effects on the desulphation process, namely: $X_{1}$ : initial $\mathrm{H}_{2} \mathrm{SO}_{4}$ rate in $\mathrm{g} / \mathrm{l}$ (reflecting the quality of phosphoric acid), $X_{2}$ the amount of barium carbonate in $\mathrm{g} / \mathrm{l}, X_{3}$ la Temperature in ${ }^{\circ} \mathrm{C}$ and $X_{4}$ the time in min. The response to be minimized is the residual rate of $\mathrm{H}_{2} \mathrm{SO}_{4}$ ( $Y$ in $\mathrm{g} / \mathrm{l}$ ). The amount of the phosphoric acid to be treated is fixed at $100 \mathrm{ml}$. The experimental field of variation of these factors (Table 5) takes into account the range of qualities that can be obtained for phosphoric acid and the operating conditions available on the industrial site.

For four factors and two levels, 16 trials $\left(2^{4}\right)$ were performed under the conditions established by the methodology of the two-levels full factorial design. The results obtained are summarized in Table 6.

Table 5. Experimental field.

\begin{tabular}{ccccc}
\hline Factors & $\begin{array}{c}\text { Amount of initial } \mathrm{H}_{2} \mathrm{SO}_{4} \\
\text { (in g/l): } X_{1}\end{array}$ & $\begin{array}{c}\text { Amount of } \mathrm{BaCO}_{3} \\
\text { (in g/l): } X_{2}\end{array}$ & $\begin{array}{c}\text { Temperature } \\
\text { (in }{ }^{\circ} \mathrm{C} \text { ): } X_{3}\end{array}$ & $\begin{array}{c}\text { Time } \\
\text { (in mn): } X_{4}\end{array}$ \\
\hline Level (-1) & 17.0 & 15 & 40 & 25 \\
Level (+1) & 29.4 & 40 & 74 & 60 \\
\hline
\end{tabular}

Table 6. Results of conducted experiments.

\begin{tabular}{|c|c|c|c|c|c|c|c|c|c|}
\hline \multirow{2}{*}{$\mathrm{N}^{\circ}$} & \multicolumn{4}{|c|}{ Codified values } & \multicolumn{4}{|c|}{ True values } & \multirow{2}{*}{$\begin{array}{c}\text { Response } \\
\text { YObs. }\end{array}$} \\
\hline & $X_{1}$ & $X_{2}$ & $X_{3}$ & $X_{4}$ & $X_{1}$ & $X_{2}$ & $X_{3}$ & $X_{4}$ & \\
\hline 1 & -1 & -1 & -1 & -1 & 17 & 15 & 40 & 25 & 8.085 \\
\hline 2 & 1 & -1 & -1 & -1 & 29.4 & 15 & 40 & 25 & 21.56 \\
\hline 3 & -1 & 1 & -1 & -1 & 17 & 40 & 40 & 25 & 0 \\
\hline 4 & 1 & 1 & -1 & -1 & 29.4 & 40 & 40 & 25 & 6.86 \\
\hline 5 & -1 & -1 & 1 & -1 & 17 & 15 & 74 & 25 & 7.84 \\
\hline 6 & 1 & -1 & 1 & -1 & 29.4 & 15 & 74 & 25 & 21.56 \\
\hline 7 & -1 & 1 & 1 & -1 & 17 & 40 & 74 & 25 & 0 \\
\hline 8 & 1 & 1 & 1 & -1 & 29.4 & 40 & 74 & 25 & 6.86 \\
\hline 9 & -1 & -1 & -1 & 1 & 17 & 15 & 40 & 60 & 7.595 \\
\hline 10 & 1 & -1 & -1 & 1 & 29.4 & 15 & 40 & 60 & 21.07 \\
\hline 11 & -1 & 1 & -1 & 1 & 17 & 40 & 40 & 60 & 0 \\
\hline 12 & 1 & 1 & -1 & 1 & 29.4 & 40 & 40 & 60 & 6.615 \\
\hline 13 & -1 & -1 & 1 & 1 & 17 & 15 & 74 & 60 & 7.84 \\
\hline 14 & 1 & -1 & 1 & 1 & 2.94 & 15 & 74 & 60 & 21.315 \\
\hline 15 & -1 & 1 & 1 & 1 & 17 & 40 & 74 & 60 & 0 \\
\hline 16 & 1 & 1 & 1 & 1 & 2.94 & 40 & 74 & 60 & 6.86 \\
\hline 17 & 0 & 0 & 0 & 0 & 23.2 & 27.5 & 57 & 42.5 & 9.065 \\
\hline
\end{tabular}

Obs.: Observed. 
The codified mathematical model is written in the form (Equation (1))

$$
\begin{aligned}
Y= & b_{0}+b_{1} X_{1}+b_{2} X_{2}+b_{3} X_{3}+b_{4} X_{4}+b_{12} X_{1} X_{2}+b_{13} X_{1} X_{3}+b_{14} X_{1} X_{4} \\
& +b_{23} X_{2} X_{3}+b_{24} X_{2} X_{4}+b_{34} X_{3} X_{4}+b_{123} X_{1} X_{2} X_{3}+b_{124} X_{1} X_{2} X_{4} \\
& +b_{134} X_{1} X_{3} X_{4}+b_{234} X_{2} X_{3} X_{4}+b_{1234} X_{1} X_{2} X_{3} X_{4}+\varepsilon
\end{aligned}
$$

where $Y$ is the amount of residual sulphate (response to be fitted and to be minimized), $X_{1}, X_{2}, X_{3}$ and $X_{4}$ (factors in codified units), $b_{0}$ is the global mean, $b_{i}$ are the effects of the main and interaction factors and $\varepsilon$ is the random error associated with the response. The results of Table 6 are treated by the JMP-SAS software to evaluate the effects of different factors with and without interaction on the residual rate of $\mathrm{H}_{2} \mathrm{SO}_{4}(Y \mathrm{in} \mathrm{g} / \mathrm{l})$ to analyze and validate the mathematical model obtained. Statistical analysis by STUDENT test for $5 \%$ risk made it possible to identify the factors having a significant influence on the observed response [8]. Table 7 present the effects, t ratio and $p$ value of each factor.

Factors that have statistically significant effects on desulphation are: $X_{1}, X_{2}$ and the interaction between them $X_{1} \times X_{2}$ ( $p$ value $\left.<0.05\right)$.

Taking into account the values of $\mathrm{t}$ ratios (Table 7 ) and the factor effects graph (Figure 5), it is found that the initial quality of the acid $\left(X_{1}\right)$ and the amount of the barium carbonate $\left(X_{2}\right)$ have a significant and antagonistic effect on the residual content of the sulphates $(Y)$ while the temperature $\left(X_{3}\right)$ and the time $\left(X_{4}\right)$ have no effect on the desulphation process due to the high affinity be-

\begin{tabular}{|c|c|c|c|c|c|}
\hline Term & $\begin{array}{c}\text { Scaled } \\
\text { Estimate }\end{array}$ & Plot Estimate & Std Error & t Ratio & Prob $>|t|$ \\
\hline Intercept & 9.0074 & & 0.0144 & 625.00 & 0.0010 \\
\hline$X_{1}$ & 5.0838 & & 0.0149 & 342.22 & 0.0019 \\
\hline$X_{2}$ & -5.6044 & & 0.0149 & -377.26 & 0.0017 \\
\hline$X_{3}$ & 0.0306 & & 0.0149 & 2.06 & 0.2875 \\
\hline$X_{4}$ & -0.0919 & & 0.0149 & -6.18 & 0.1021 \\
\hline$X_{1} \times X_{2}$ & -1.6844 & & 0.0149 & -113.39 & 0.0056 \\
\hline$X_{1} \times X_{3}$ & 0.0306 & & 0.0149 & 2.06 & 0.2875 \\
\hline$X_{1} \times X_{4}$ & -0.0306 & & 0.0149 & -2.06 & 0.2875 \\
\hline$X_{2} \times X_{3}$ & 0.0000 & & 0.0149 & 0.00 & 1.0000 \\
\hline$X_{2} \times X_{4}$ & 0.0613 & & 0.0149 & 4.12 & 0.1515 \\
\hline$X_{3} \times X_{4}$ & 0.0613 & & 0.0149 & 4.12 & 0.1515 \\
\hline$X_{1} \times X_{2} \times X_{3}$ & 0.0000 & & 0.0149 & 0.00 & 1.0000 \\
\hline$X_{1} \times X_{2} \times X_{4}$ & 0.0000 & & 0.0149 & 0.00 & 1.0000 \\
\hline$X_{1} \times X_{3} \times X_{4}$ & 0.0000 & & 0.0149 & 0.00 & 1.0000 \\
\hline$X_{2} \times X_{3} \times X_{4}$ & -0.0306 & & 0.0149 & -2.06 & 0.2875 \\
\hline$X_{1} \times X_{2} \times X_{3} \times X_{4}$ & 0.0306 & & 0.0149 & 2.06 & 0.2875 \\
\hline
\end{tabular}
tween barium ions and sulphate ion.

Table 7. Analysis of the effects of variables. 


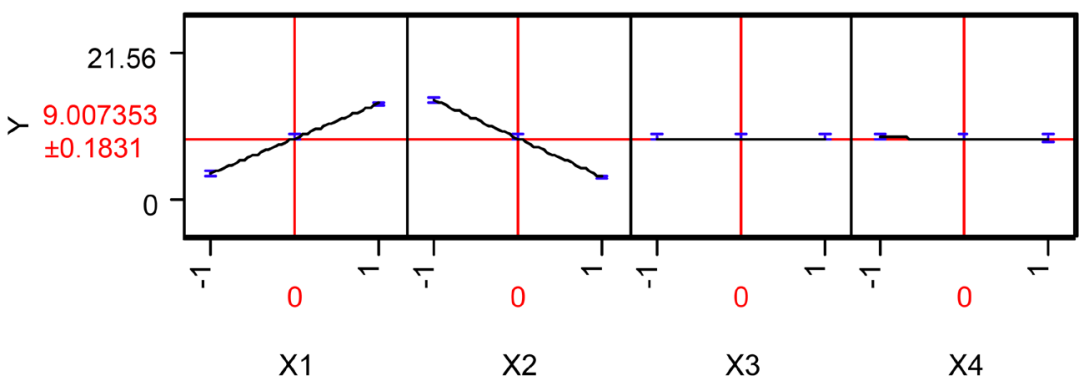

Figure 5. Effects of factors on the desulphation of phosphoric acid $29 \% \mathrm{P}_{2} \mathrm{O}_{5}$.

The mathematical model is therefore written in the form (Equation (2)):

$$
Y=9.0074+5.0838 * X_{1}-5.6044 * X_{2}-1.6844 * X_{1} * X_{2}
$$

ANOVA (Analysis of variance) shown in Table 8 confirms the statistical validity of the mathematical model with a determination factor $R^{2}$ of $99.96 \%$. The graphical fit of the model (Figure 6) shows that the estimated responses $\left(Y_{\text {est }}\right)$ by the experimental data with a correlation factor $R^{2}=99.9 \%$.

Additional tests (Table 9) were carried out in the experimental field with experimental conditions not used in the experimental matrix (Table 6). The residual between the observed ( $\left.Y_{\text {obs }}\right)$ and the estimated $\left(Y_{\text {est }}\right)$ results is not significant. The desulphation protocol can therefore be represented by the mathematical model (Equation (2)) in order to determine the optimum experimental conditions for efficient reduction of sulphates, depending on the quality of the phosphoric acid to be treated $\left(X_{1}\right)$.

For economic reasons, 29\% $\mathrm{P}_{2} \mathrm{O}_{5}$ phosphoric acid can be pre-treated at its temperature upon its arrival in the desulphation reactor $\left(74^{\circ} \mathrm{C}\right)$ and for a time which does not affect the phosphoric acid manufacturing process (60 min). Depending on the phosphoric acid quality to be pre-treated, the amount of barium carbonate is determined using Equation (3) where $Y$ Tolerated is the maximum residual amount of $\mathrm{H}_{2} \mathrm{SO}_{4}$ having no effect on the formation of deposit solid during the phosphoric acid concentration step.

$$
X_{2}=\frac{9.0074-Y_{\text {tolerated }}+5.0838 * X_{1}}{5.6044+1.6844 * X_{1}}
$$

According to Table 2, phosphoric acid 54\% $\mathrm{P}_{2} \mathrm{O}_{5}$, obtained from $29 \% \mathrm{P}_{2} \mathrm{O}_{5}$ acid non-desulphated, is saturated with sulphate and calcium $\left(2.95 \% \mathrm{SO}_{4}^{2-}\right.$ and $0.68 \% \mathrm{CaO}$ ) which corresponds to a concentration of $49.59 \mathrm{~g} / \mathrm{l}$ of sulphate and $8.16 \mathrm{~g} / \mathrm{l}$ of calcium given a solubility product of $404.89(\mathrm{~g} / \mathrm{l})^{2}$. In the case of desulphation the mass of the calcium initially present in the acid $29 \%$ is preserved in the acid $54 \%$ with a concentration of $17.25 \mathrm{~g} / \mathrm{l}$. Therefore, the sulphate concentration in the $54 \%$ acid at saturation should be $23.46 \mathrm{~g} / \mathrm{l}$. The maximum residual mass of Tolerated Sulphate $Y_{\text {Tolerated }}$ is $8.97 \mathrm{~g} / \mathrm{l}$.

For example, for an initial acid with quality of $X_{1}=22 \mathrm{~g} \mathrm{H}_{2} \mathrm{SO}_{4} / 1$ and $Y_{\text {Tolerated }}=$ $8.97 \mathrm{~g} / \mathrm{l}$, the amount of $\mathrm{BaCO}_{3}$ to be used for desulphation is $25.25 \mathrm{~g} / \mathrm{l}$. After concentration of the desulphated acid, the total amount of the formed solid is 


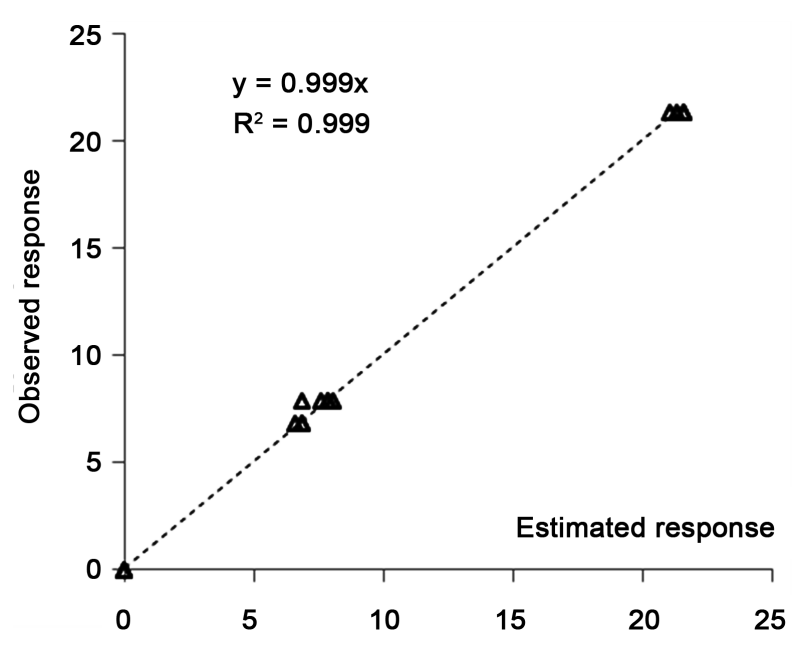

Figure 6. Adjustment graph.

Table 8. Analyze of variance (ANOVA).

\begin{tabular}{ccccc}
\hline & DF & Sum of Squares & Mean Square & F Ratio \\
\hline Source & 3 & 961.45044 & 320.4835 & 11649.09 \\
Error & 12 & 0.33014 & 0.0275 & \\
Model & 15 & 961.78057 & 64.1187 & \\
\hline
\end{tabular}

Table 9. Results of additional tests.

\begin{tabular}{ccccccc}
\hline $\begin{array}{c}\text { Amount of } \mathrm{H}_{2} \mathrm{SO}_{4} \\
\text { (in g/l): } X_{1}\end{array}$ & $\begin{array}{c}\text { Amount of } \mathrm{BaCO}_{3} \\
\text { (in g/l): } X_{2}\end{array}$ & $\begin{array}{c}\text { Temperature } \\
\text { (in }{ }^{\circ} \mathrm{C} \text { ) }: X_{3}\end{array}$ & $\begin{array}{c}\text { Time } \\
\text { (in mn): } X_{4}\end{array}$ & $\begin{array}{c}Y \text { Obs. } \\
\text { (in g/l) })\end{array}$ & $\begin{array}{c}Y \text { Est. } \\
\text { (in g/l) }\end{array}$ & Residual \\
\hline 21.8 & 31 & 57 & 42.5 & 6.125 & 6.397 & -0.272 \\
21.8 & 16 & 74 & 25 & 12.740 & 12.666 & 0.074 \\
23.2 & 27.5 & 57 & 42.5 & 9.065 & 9.007 & 0.058 \\
29.4 & 20 & 74 & 25 & 18.620 & 18.464 & 0.156 \\
\hline
\end{tabular}

Obs.: Observed; Est.: Estimated.

$0.37 \%$ instead of $2.24 \%$ (Table 2), without taking into account the solid deposited at the heat exchanger for the second value. This represents a reduction rate of formed solid around $83.5 \%$ at least.

For industrial scale, desulphation by barium carbonate can be carried out directly at the level of the aging tank without addition of specific equipment to the phosphoric acid manufacturing unit (Figure 7).

\section{Conclusion}

Deposition of gypsum during the $29 \% \mathrm{P}_{2} \mathrm{O}_{5}$ phosphoric acid concentration stage is a real technical-economic problem for producing phosphoric acid $54 \% \mathrm{P}_{2} \mathrm{O}_{5}$. Physico-chemical characterization by ICP-OES and X-ray diffraction showed that this deposit is mainly composed by gypsum and low amount of fluosilicates. Desulphation of phosphoric acid $29 \% \mathrm{P}_{2} \mathrm{O}_{5}$ by barium carbonate will reduce the 


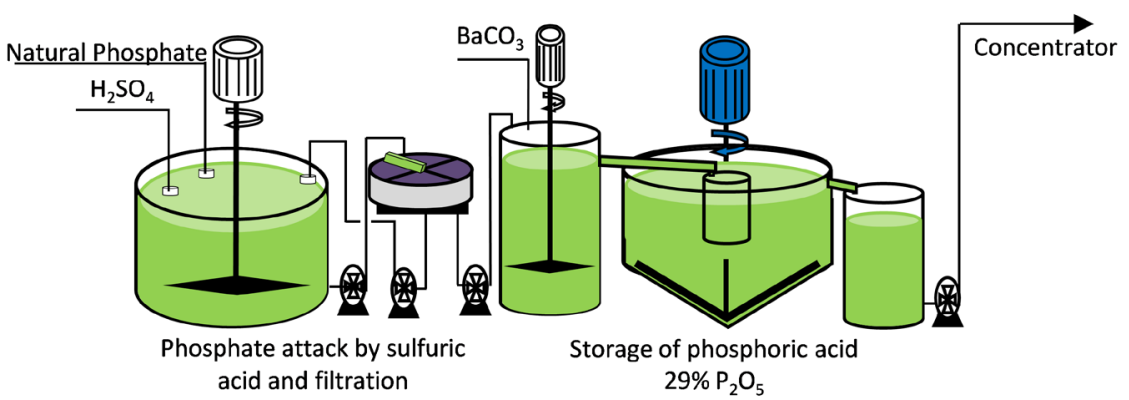

Figure 7. Phosphoric acid manufacturing steps with desulphation by barium carbonate.

formation of gypsum in the concentrator. The proposed desulphation protocol can be easily inserted into the industrial process; it is limited to a simple attack of phosphoric acid $29 \% \mathrm{P}_{2} \mathrm{O}_{5}$ by $\mathrm{BaCO}_{3}$ under stirring. Regarding to DOE methodology based on the strategy of full factorial design, taking into account the initial amount of $\mathrm{H}_{2} \mathrm{SO}_{4}$ in phosphoric acid $29 \% \mathrm{P}_{2} \mathrm{O}_{5}$, the amount of barium carbonate, temperature and reaction time, it has been shown that only the quality of the acid and the amount of $\mathrm{BaCO}_{3}$ have a significant effect on desulphation. The model obtained is validated with $R^{2}=99.96 \%$ and can be used to determine the effective amount of $\mathrm{BaCO}_{3}$ as a function of the phosphoric acid quality and the maximum residual mass of $\mathrm{H}_{2} \mathrm{SO}_{4}$ to avoid the formation of gypsum. The amount of the solid formed can therefore be reduced to $83.5 \%$. This improves the production cycle and reduces maintenance and operating costs.

\section{Acknowledgements}

"Research carried out within the framework of the University Center for Research Applied Chemistry and Sustainable Development CUR CA2D of Chouaïb Doukkali University".

\section{Conflicts of Interest}

The authors declare no conflicts of interest regarding the publication of this paper.

\section{References}

[1] Becker, P. (1989) Phosphates \& Phosphoric Acid: Row Materials, Technology \& Economics of the Wet Process. 2nd Edition, Marcel Dekker, New York.

[2] Hignett, T.P. (1980) Proceedings of Second International Congress on Phosphorous Compounds, Boston, 21-25 April 1980, 401-429.

[3] Kirfel, A. and Will, G. (1980) Charge Density in Anhydrite, $\mathrm{CaSO}_{4}$, from $X$-Ray and Neutron Diffraction Measurements. Acta Crystallographica Section B, 36, 2881-2890. https://doi.org/10.1107/S0567740880010461

[4] Cipriani, C. (1955) Structure of $\mathrm{Na}_{2} \mathrm{SiF}_{6}$ and $\mathrm{Na}_{2}$ GeF. Rend. Soc. Mineral. Ital., 11, 58.

[5] Pereira, P. (2003) Phosphoric Acid Production by Hydrochloric Attack of Phosphate Ores with Reduction of Environmental Nuisances and Recovery of Rare 
Earths as By-Products Geochemistry. National School of Mines of Saint-Etienne, France.

[6] Bott, R.T. (1995) Fouling of Heat Exchangers. Elsevier Science \& Technology Books, Amsterdam.

[7] Montgomery, D.C. (1997) Design and Analysis of Experiments. 4th Edition, John Wiley and Sons, New York.

[8] Hebbar, A. (2006) Statistical Methods of Extreme Planning of Experiments. University of Mostaganem, Mostaganem, 71-72. 